\title{
Дистанционное обучение английскому языку в системе Moodle (метод синергетического стимулирования)
}

\author{
Панкратова C.A. \\ Санкт-Петербургский государственный институт кино и телевидения, \\ Россия, 191119, г. Санкт-Петербург, ул. Правды, 13 \\ E-mail: svetpankrat@yandex.ru
}

\begin{abstract}
Аннотация. Автор обращается к значимой проблеме повышения качества дистанционного обучения на примере применения метода синергетического стимулирования. На современном этапе проблема остается активно дискутируемой, идет наработка практических и теоретических основ дистанционного обучения для оптимизации процесса освоения иностранного языка в системе Moodle. В связи с этим рассмотрена проблема дистанционного обучения английскому языку в кинематографическом вузе с учетом эмоциональной составляющей процесса обучения онлайн. Выявлены неочевидные плюсы и минусы дистанционного образования. Предлагаемый метод синергетического стимулирования позволяет сформировать шкалу студенческого прилежания и академической успеваемости и может быть полезен как частным языковым школам, так и государственным образовательным учреждениям. Метод реализуется в онлайнкоммуникации на английском языке и способствует стимулированию студенческого интереса к изучению языка. Составлена девятибалльная шкала студенческой успеваемости согласно российским и английским градациям. Даны языковые примеры персонализированного стимулирования студентов преподавателем.
\end{abstract}

Ключевые слова: электронное обучение, очное обучение, онлайн-обучение, синергетическое стимулирование, система Moodle.

Для цитирования: Панкратова С.А. 2020. Дистанционное обучение английскому языку в системе Moodle (метод синергетического стимулирования). Вопросы журналистики, педагогики, языкознания, 39 (3): 432-442. DOI 10.18413/2712-7451-2020-39-3-432-442

\section{The distance teaching of the English language in the Moodle system (the method of synergetic stimulation)}

\author{
Svetlana A. Pankratova \\ Saint Petersburg State Institute of Film and Television, \\ 13 Pravda St, Saint-Petersburg, 191119, Russia \\ E-mail: svetpankrat@yandex.ru
}

\begin{abstract}
The article treats a significant problem of improving the quality of education on the example of the synergetic stimulation method. The modern stage of education continues to discuss the problem, practical and theoretical development of methods of distance learning are in progress, which helps learning English language in the Moodle system. The paper reveals the key elements of the distant teaching of the English language in the cinematographic institute considering the emotional component of the educational process. Not so obvious sides of the distance learning are revealed. The film discourse as a complex communicative phenomenon requires the development of communicative skills among young specialists and laymen outside the film sphere. The method of synergetic stimulation (the method of «husky team») is used to demonstrate how poor achievers working in a group are able to get an
\end{abstract}


impression of their performance and knowledge gaps, which serves as an impulse to make efforts. Educational uniformity is thus achieved as a result of an intense stream exchange of the energy which is motivating students to look for solutions in a team, collectively making efforts. The nine-point scale of student diligence and academic achievement is offered. Based on these, the study concludes in formulating the ways for extensive peer and teacher support. In the summary it is stated that distance learning in the Moodle system facilitated by teachers' emotional support and personalised evaluation can provide support for students forming their professional skills in the online mode of learning.

Keywords: E-learning, face-to-face learning, online learning, synergetic stimulation method, Moodle system.

For citation: Pankratova S.A. 2020. The distance teaching of the English language in the Moodle system (the method of synergetic stimulation). Issues in Journalism, Education, Linguistics, 39 (3): 432-442 (in Russian). DOI 10.18413/2712-7451-2020-39-3-432-442

\section{Введение}

Повсеместное и форсированное внедрение в образование компьютерных технологий, направляющих информационные потоки и формирующих взаимосвязанную образовательную информационную среду, есть отличительная черта последнего десятилетия. В наши дни внедрение дистанционного обучения посредством компьютера стало жизненной необходимостью в связи с пандемией коронавруса Covid-19.

Для понимания перспектив развития дистанционного обучения важно изучение особенностей функционирования техногенных обществ с информационнокоммуникативными технологиями. Специалисты в области информационных коммуникаций давали разнообразные именования современному периоду развития общества: «ноосферное» (А.И. Вернадский), «информационное» (Т. Умесао), «информационнокомпьютерное» (Й. Масуда, Ф. Уэбстер), «программируемое» (А. Турен), «техноторонное и пост-индустриальное» (Д. Белл, 3. Бжезинский, Дж. Ваттимо, Л. Хиршхорн), «супериндустриальное» (О. Тоффлер).

Итогом прогресса к началу XX века становится развертывание научно-технической революции и последовавшей за ней информационно-коммуникативной революции, обусловленной переходом на совершенно иную, постиндустриальную стадию развития. Перестройка современного глобализующегося мира в сторону экономики, основанной на знаниях и интеллектуальном капитале, по техническим меркам оказывается медленным, но неуклонным процессом. Благодаря технологической рационализации социального и природного пространства мира меняется и модель современного образования, в число участников образовательного процесса помимо преподавателя и студента включается и третий - персональный компьютер.

Существует пробел в методике образования, связанный с недостаточным освещением эмоционального компонента дистанционного образования как стимула к синергетическому образовательному росту. В связи с этим цель настоящего исследования состоит в совершенствовании методологии дистанционного обучения. Необходимо не ограничивать образование приобретением отдельных компетенций, а развивать глубокое понимание предмета, учить студентов создавать творческий, а отнюдь не репродуктивный информационный контент. Автором рассмотрены перспективы изменений образовательного процесса в связи с внедрением дистанционного обучения английскому языку на примере Санкт-Петербургского государственного института кино и телевидения. 


\section{Объект и методы исследования}

Объектом исследования является процесс дистанционного обучения иностранному (английскому) языку на первом этапе образования (1 и 2 курсы) в кинематографическом вузе. Предметом исследования являются особенности внедрения дистанционного обучения на заявленном этапе. Методы исследования включали изучение и анализ психологопедагогической литературы, анализ государственных образовательных стандартов и рабочих программ, наблюдение за процессом обучения иностранному языку на общепрофессиональном этапе, критическую оценку данных, полученных в наблюдении. Метод непосредственного наблюдения за успеваемостью студентов позволил выявить группы по способностям к обучению для калибровки персонализированного подхода к дистанционному обучению. Метод управляемых открытий (guided discovery) опирается на контекст в решении задач коллективом студентов. «Метод заключается в презентации студентам изучаемых явлений в контексте, правила при этом не формулируются. Затем при помощи преподавателя студенты открывают для себя определенные закономерности, делают общий вывод, формулируют правило» [Герасимова, 2019, с. 344].

Еще одним инновационным методом является предложенный автором метод синергетического стимулирования (метод «упряжки лаек»), когда слабоуспевающие студенты, работая в группе, получают представление о своих пробелах в знаниях и импульс к работе над собой. Это подобно тому, как слабо тянущие упряжку лайки слышат лай, чувствуют покусывания более сильных и включаются в общее дело. При этом отстающие получают импульс к саморазвитию не только и не столько от преподавателя, сколько наблюдая сложившуюся в аудитории продуктивную поисковую деятельность, в которую им хочется внести вклад.

\section{Результаты и их обсуждение}

В самом начале обсуждения необходимо определиться с терминами «дистанционное обучение», «онлайн обучение» и «электронное обучение». Сам термин «электронное обучение» пришел к нам из английского языка (от англ. e-learning) и обозначает электронное обучение с использованием Интернета. Существуют источники, уравнивающие статус онлайн и дистанционного обучения: «...дистанционное образование: 1) online education» [Lingva-pro, 2020]. Позволим себе не согласиться с подобной расширенной трактовкой, не учитывающей непостоянность интернета. Если онлайн-образование предполагает общение лицом к лицу в реальном времени, то о дистанционном образовании этого не скажешь. В поддержание нашего мнения приведем синонимы к слову «дистанционный»: удаленный (от англ. remote), по переписке (от англ. learning via correspondence). Исторически дистанционное образование зародилось еще в 1728 году, когда Калеб Филипс через бостонскую газету объявил о наборе студентов-стенографистов для обучения в любой точке США путем обмена писем [Aspillera, 2010; Miller, 2014]. Ключевым компонентом дистанционного обучения является возможность связаться с образовательным порталом, чтобы получить задания, загрузить свои ответы.

Плюсами дистанционного обучения можно считать следующее: ненадобность траты времени на передвижение, разнообразие учебных программ, возможность повтора, отсутствие проблем социализации, инклюзивность. К недостатками можно причислить низкое качество полученных знаний, необходимость сильнейших волевых усилий, асоциальность, уравнительность, неэмоциональность. В военных вузах, где курсанты строем ходят на занятия, заступают в наряды, проходят вместе строевую подготовку, эта форма слабо применима из-за невозможности курсантов уединиться у компьютера. Дистанционное образование нереализуемо на олимпиадах и конкурсах, где как раз развивается соревновательный дух и азарт в достижении решений. 
В рамках электронных информационных образовательных систем (ЭИОС) РФ в каждом вузе формируется среда, состоящая из официального сайта вуза, электронной библиотечной среды, портала балльно-рейтинговой системы и образовательного дистанционного портала. Все учебные планы и рабочие программы цифровизуются и дублируются в модульной объектно-ориентированной динамической обучающей среде (Moodle), оценивающей успеваемость как автоматически, так и персонально (в форме прикрепленных текстовых- и аудиозаданий). Декларативно высшее образование нацелено на достижение разнообразных результатов (компетентностей): предметных (получение знаний, умений, навыков и опыта), метапредметных (освоение комуникативных и познавательных способов деяельности) и личностных (формирование системы ценностных отношений к себе, обучению и другим). Высшее образование ставит комплексные задачи формирования человека высокомотивированного, амбициозного и самостоятельно выстраивающего свою образовательную траекторию на протяжении всей жизни.

Преимущество современных молодых людей в том, что они с легкостью ориентируется в мировых информационных потоках. Одним из существенных недостатков является то, что студенты становятся несамостоятельны, несамокритичны и неорганизованны. Их поисковая активность направлена «...на поиск и копирование готового решения задачи, а не на поиск способов ее решения» [Ильченко, Максимова, 2019, с. 125]. В новейшей ситуации вынужденного перехода на дистанционное обучение все эти недостатки усугубляются. Меняется когнитивный стиль первокурсников, принадлежащих к поколению Y и Z (рожденные в период с 1981-2003 и после 2003 года). У них отмечается динамичное клиповое мышление и неспособность концентрировать внимание, неумение вдумчиво читать, выделяя главное. Потребность в бдительном контроле и буквальном объяснении «на пальцах» со стороны преподавателя снижает методологическую планку преподавания. Студенты все менее способны построить разговор вживую, сформулировать мысль, грамотно перефразировать текст, дают «рваные» односложные ответы, затягивают паузы, отмалчиваются.

Другой стороной становится отсутствие границ и рамок в общении по модели интернета, где «...можно начать общаться с любым человеком, независимо от социального статуса и роли, отношения при этом априори подразумеваются дружескими» [Сулоева, Романцова, 2019, с. 640]. Для оптимизации такого способа получения знаний зарубежные исследователи М. Оливер и К. Тигвелл предлагают применять в дистанционном обучении ряд технологий и педагогических подходов, основанных на четырех образовательных теориях: «constructivism, behaviorism, connectivism and cognitivism, to meet challenges and to optimize students' learning process» (конструктивизм, бихевиоризм, коннективизм и когнитивизм для решения сложных задач и оптимизации прочесса обучения студентов) [Oliver, Tigwell, 2005, p. 17]. Важными здесь видятся именно поведенческий аспект и учет познавательных задатков, равно как и связь с обучающей средой, коммуникация.

Жестко и нелицеприятно о действительных, а не декларативных целях образования сказано белорусским ученым А.В. Мякинькой, обратившей внимание на образовательный протекционизм Евросоюза, рассматривающего вуз как «...супермаркет или базар, где объявили сезонную распродажу, а учеников и студентов рассматривают как покупателейпотребителей. Владельцы заводов, шахт, пароходов желают видеть таких исполнителей, которые владеют определенными компетенциями и навыками, необходимыми ему, работодателю. А из этого вытекает очевидное: вместо специалиста с высоким уровнем фундаментальных научных знаний, человеческими качествами и моралью, в чем исключительная роль принадлежит социально-гуманитраному образованию, появится человек с узкоспециализированными компетенциями, неспособный адаптироваться к условиям, который 
будет покупать новые и новые компетенции всю трудовую жизнь и платить, платить, платить дельцам от образования» [Мякинькая, 2019, с. 519].

Нельзя не согласиться с размышлениями автора, но нельзя и впадать в образовательный пессимизм. По нашему мнению, все зависит от сознательности участников образовательного процесса, их желания повышать его качество. На деле наблюдается «...снижение интеллектуального и общеобразовательного уровня обучающихся, недостаточность сформированности навыков устной речи, пространственно-временная и георгафическая дезориентация, неумение аргументировать свою позицию, слабая логика анализа общественных событий» [Андреева, 2019, с. 623]. Качественная цифровизация образования подразумевает полноценное сопровождение преподавателя-предметника цифровыми специалистами: дизайнерами, методистами, IT специалистами. «Цифровизация - создание качественного учебного продукта, а не попытка сэкономить бюджет учебного заведения за счет сокращения аудиторной нагрузки и последующего сокращения кадров» [Московчук, 2019, с. 568].

Мы полагаем, что критерием освоения дисциплин дистанционно может послужить освоение так называемых надпрофессиональных навыков общения (от англ. soft skills). Этого ожидает рынок труда, где начало профессиональной деятельности не подразумевает высокого профессионализма, но настойчиво предъявляет требование переподготовки для адаптации к запросам работодателей. «С точки зрения работодателя для профессионала важны креативность, убедительность, коллаборация, адаптируемость, управление временем, развитые навыки обработки информации, мышления, системного дизайна, но они не развиваются через персональный компьютер, однако на практике имеют первоочередное значение» [Вознесенская, Шехонин, 2019, с. 470].

Итак, на первый план при дистанционном образовании выдвигается проблема недостатка живого контакта лицом к лицу. «Хороший учитель не просто реагирует на сильные и слабые стороны ученика, но он чутко откликается на его душевное состояние, стремится максимизировать человеческий потенциал. Студенты также полагаются на учителей для руководства жизнью и наставничества. Глубокое и содержательное человеческое взаимодействие имеет решающее значение и его очень сложно даже невозможно автоматизировать полностью» [Шелудько и др., 2019, с. 5]. Того же мнения придерживаются и зарубежные педагоги, ратующие в пользу смешанной формы, комбинирующей персонализированное и онлайн-обучение: «...blended learning is beneficial for students as a combination of 'face-to-face and online learning'» (... смешанное обучение полезно для студентов как сочетание "очного и онлайн-обучения") [Graham, 2006; Stacey, Gerbic, 2009, p. 18].

Доступность цифровой информации становится «...соблазном для учеников, склонных к лени. Намного проще найти готовый ответ, ведь наверняка кто-то уже задавался этим вопросом, достаточно набрать вопрос в поисковой строке» [Пояркова, 2019, с. 440]. А найти преподавателя, готового создавать уникальные задания нелегко. К сожалению, «...контроль тестами знаний на уровне логических действий (доказать, обосновать, сделать вывод) и на уровне воспроизведения, умения, интерпретации, анализа остается за скобками» [Шабаева, 2019, с. 554]. Упор в основном делается на формальное запоминание шаблонов, делает их беспомощными перед нестандартными ситуациями. Вместе с тем, электронная образовательная среда Moodle интересна сочетанием как репродуктивных (работа с загруженными в систему текстами, решение типовых тестов), так и продуктивных (выполнение творческих проектных заданий в виде докладов, исследований и презентаций) заданий.

Выход видится в комплексном образовательном подходе, задействующем как интеллект, так и эмоциональный фон обучающихся. Необходимы стратегии персонализированного обучения в онлайн-среде, которые помогут повысить вовлеченность студентов в 
обучение. Действительно, использование дистанционных методов образования служит подспорьем, умножителем ментальных способностей студента. Персонализированный индивидуальный подход должен принимать во внимание и аудио-визуальнокинестетическую типологию личности, те самые 90 \% людей, зрительно воспринимающих мир в соотношении к $9 \%$ слышащих мир и к $1 \%$ настроенных на канал обоняния, вкуса и осязания. Помимо каналов восприятия, есть и проблема скорости и глубины подачи, когдалибо слабые не успевают за сильными, либо сильным скучно. Все эти аспекты устанавливаются и отлаживаются в живом контакте с преподавателем. «В персонализированном обучении главное для учащегося не программное обеспечение или интернет, а общение с учителем, студентами и преподавателями вузов, во время которого обсуждаются научные проблемы, намечаются пути их решения, идет обмен опытом» [Яковлева и др., 2019 , c. 446].

Персонализированный подход включает мотивационный уровень студентов. Согласно разработке И.А. Лапина и И.А. Лапиной [2019], есть несколько уровней мотивации студентов: 1) нулевая с полным отсутствием потребности к деятельности, 2) очень низкая у трудновоспитуемых, быстропереключающихся студентов, уверенных в необходимости быстрых заработков, 3) слабая с высокой самооценкой, большими запросами к преподавателям и неуважением, 4) средняя с всплесками неповиновения, 5) высокая у полностью организованного мотивированного студента. Авторы утверждают, что в процентном соотношении «...студенты 1-й и 2-й групп составляют порядка десяти процентов и 90 \% из них отчисляются. Студенты 3-й и 4-й групп составляют 60 \% обучающихся и из них отчисляются порядка 50 \%. Из 5-й группы, составляющей примерно тридцать процентов, отчислению подлежит 10 \%» [Лапин, Лапина 2019, с. 585]. Делается вывод, что необходим непрестанный строгий контроль, такт и внимание родителей и преподавателей. Сохранить интерес и не потерять студентов поможет эмотивная составляющая образования. Для этого преподаватели должны развивать эмоциональный интеллект (EQ - emotional quotient), умение не только «разложит все по полочкам», но и дать мощный мотивационный толчок. «Сегодня лучше сосредоточиться на эмоциональной теплоте и "танцевать" от эмоций студента» [Меркулова, 2019, с. 293], констатируя старые знания как основу для дальнейшего саморазвития.

Авторская разработка метода синергетического стимулирования (метод «упряжки лаек»), когда слабоуспевающие студенты, работая в группе, получают представление о своих пробелах в знаниях и импульс к работе над собой, позволила выделить группы студентов и предложить персонализированный подход. Как представляется, поддержка и одобрение являются тем недостающим элементом, который утрачивается при дистанционном обучении в наши дни. От преподавателя требуется высокий эмоциональный интеллект, сопереживание успехам и неуспехам студентов, желание подтолкнуть к открытиям. В слабой группе (сачок, полуребенок, любитель) требуется особая чуткость, чтобы не отбить интерес учащихся. В средней группе (импровизатор, исполнитель, звезда) следует обратить внимание на творческие отклонения, дисциплинировать студентов. В сильной группе (интеллектуал, реалист, эксперт) требуется высокий профессионализм, начитанность, чтобы направить студентов к высотам профессии. Это требует от преподавателя самоотдачи и настроя.

Система оценивания исходит из реально работающих в российском образовании трех баллов - «удовлетворительно», «хорошо» и «отлично» (см. таблицу). В таблице 1 каждый подтип получил бинарное наименование (заглавными буквами) исходя из прилежания, задатков, базовых знаний, креативности и рационального отношения к учебным ресурсам. Психологические подтипы даны ниже (выделение подчеркиванием). Необходи- 
мая каждому типу поддержка от преподавателя представлена после каждого подтипа (курсивом).

Девятибалльная шкала оценки прилежания и успехов студентов

Nine-point scale of student diligence and academic achievement

\begin{tabular}{|c|c|c|c|c|c|c|c|c|c|}
\hline 具 & \multicolumn{3}{|c|}{ Слабоуспевающие } & \multicolumn{3}{|c|}{ Успевающие } & \multicolumn{3}{|c|}{ Выдающиеся } \\
\hline 离 & $\begin{array}{l}\text { SHIRK } \\
\text { ER } \\
\text { (сачок) }\end{array}$ & $\begin{array}{c}\text { KIDULT } \\
\text { (недо- } \\
\text { взрос- } \\
\text { лый) }\end{array}$ & $\begin{array}{c}\text { AMA- } \\
\text { TEUR } \\
\text { (люби- } \\
\text { тель) }\end{array}$ & $\begin{array}{c}\text { AD- } \\
\text { LIBBER } \\
\text { (импро- } \\
\text { визатор) }\end{array}$ & $\begin{array}{c}\text { DOER } \\
\text { (трудя- } \\
\text { га) }\end{array}$ & $\begin{array}{l}\text { SPARK } \\
\text { (звезда) }\end{array}$ & $\begin{array}{l}\text { HIGH- } \\
\text { BROW } \\
\text { (интел- } \\
\text { лектуал) }\end{array}$ & $\begin{array}{l}\text { REAL- } \\
\text { IST (pe- } \\
\text { алист) }\end{array}$ & $\begin{array}{l}\text { EX- } \\
\text { PERT } \\
\text { (экс- } \\
\text { перт) }\end{array}$ \\
\hline 氺 & 3- & 3 & $3+$ & 4- & 4 & $4+$ & 5- & 5 & $5^{+}$ \\
\hline 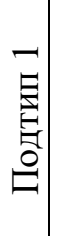 & $\begin{array}{l}\frac{\text { Mono- }}{\underline{\text { syl- }}} \\
\underline{\text { labic }} \\
\underline{\text { new- }} \\
\underline{\text { bie: }}\end{array}$ & $\begin{array}{r}\text { Gutless } \\
\text { nuisance: }\end{array}$ & $\frac{\frac{\underline{\text { Luke- }}}{\text { warm }}}{\frac{\underline{\text { mediocri- }}}{\text { ty: }}}$ & $\begin{array}{l}\frac{\text { Enthusi- }}{\text { ast eager }} \\
\text { beaver: }\end{array}$ & $\begin{array}{l}\frac{\text { Disci- }}{\text { plined }} \\
\underline{\text { swot: }}\end{array}$ & $\frac{\text { Original }}{\frac{\text { maver- }}{\underline{\text { ick: }}}}$ & $\frac{\underline{\text { Intelli- }}}{\text { gent nud- }} \frac{\text { nik: }}{\underline{\text { nent }}}$ & $\begin{array}{l}\frac{\text { Clear- }}{\text { thinking }} \\
\frac{\text { pragma- }}{\underline{\text { tist: }}}\end{array}$ & $\begin{array}{l}\frac{\text { Fault- }}{\text { less }} \\
\text { trouble- } \\
\text { shooter: }\end{array}$ \\
\hline 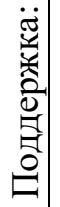 & $\begin{array}{l}\text { Take } \\
\text { wing, } \\
\text { lame } \\
\text { duck! }\end{array}$ & $\begin{array}{c}\text { Bug out } \\
\text { when it } \\
\text { gets } \\
\text { tough? }\end{array}$ & $\begin{array}{l}\text { The fat of } \\
\text { knowledg } \\
\text { e living? }\end{array}$ & $\begin{array}{c}\text { Slow'n } \\
\text { steady } \\
\text { wins the } \\
\text { race! }\end{array}$ & $\begin{array}{c}\text { It's } \\
\text { dogged } \\
\text { that } \\
\text { does it! }\end{array}$ & $\begin{array}{c}\text { Get } \\
\text { more } \\
\text { left- } \\
\text { brained! }\end{array}$ & $\begin{array}{l}\text { Don't } \\
\text { love half- } \\
\text { truths? }\end{array}$ & $\begin{array}{c}\text { Looking } \\
\text { for } \\
\text { shortcut } \\
\text { s? }\end{array}$ & $\begin{array}{c}\text { On your } \\
\text { mental } \\
\text { toes! }\end{array}$ \\
\hline 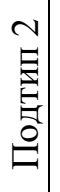 & $\begin{array}{l}\frac{\text { Men- }}{\text { tally }} \\
\frac{\text { lazy }}{\text { ghost: }}\end{array}$ & $\begin{array}{l}\frac{\text { Superfi- }}{\text { cial air- }} \\
\underline{\text { head: }}\end{array}$ & $\frac{\text { Doubtful }}{\frac{\text { smart }}{\underline{\text { alec: }}}}$ & $\begin{array}{l}\text { Green- } \\
\underline{\text { lamer: }}\end{array}$ & $\begin{array}{l}\begin{array}{c}\text { Persis- } \\
\text { tent } \\
\text { overa- } \\
\text { chiever: }\end{array} \\
\end{array}$ & $\begin{array}{l}\frac{\text { Inde- }}{\text { pendent }} \\
\underline{\text { free }} \\
\underline{\text { lancer: }}\end{array}$ & $\begin{array}{l}\text { Dawdling } \\
\text { perfec- } \\
\text { tionist: }\end{array}$ & $\frac{\text { Practical }}{\underline{\text { artful }}}$ & $\frac{\text { Mature }}{\text { geek: }}$ \\
\hline 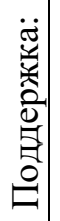 & $\begin{array}{l}\text { Get } \\
\text { your } \\
\text { act } \\
\text { togeth- } \\
\text { er! }\end{array}$ & $\begin{array}{l}\text { Learning } \\
\text { by fits } \\
\text { and } \\
\text { starts? }\end{array}$ & $\begin{array}{l}\text { Bite off } \\
\text { more } \\
\text { than } \\
\text { chew? }\end{array}$ & $\begin{array}{c}\text { In the } \\
\text { passenger } \\
\text { seat? }\end{array}$ & $\begin{array}{c}\text { Making } \\
\text { a } \\
\text { breakth } \\
\text { rough! }\end{array}$ & $\begin{array}{c}\text { In Rome } \\
\text { do as } \\
\text { Romans } \\
\text { do! }\end{array}$ & $\begin{array}{c}\text { When in } \\
\text { doubt, do } \\
\text { nowt? }\end{array}$ & $\begin{array}{l}\text { Fortunes } \\
\text { in a } \\
\text { teacup? }\end{array}$ & $\begin{array}{c}\text { Streets } \\
\text { ahead } \\
\text { of the } \\
\text { rest! }\end{array}$ \\
\hline
\end{tabular}

\section{Выводы}

Информатизация уже давно является объективной данностью для современного российского образования, в котором активно внедряется дистанционное обучение в рамках электронных информационных образовательных систем (ЭИОС). Несомненно, классическое институциональное обучение не уступит место дистанционному, но смешанный формат обучения (blended education), сочетающий онлайн- и оффлайн-методы будет получать все более широкое применение [Graham, 2006; Macdonald, 2007]. Преподаватель не может и не должен быть вытеснен из образовательного процесса, а его роль в установлении эмоционального контакта и стимулировании мотивации как никогда высока. Даже в дистанционной форме обучения эмоциональный импульс и поддержка преподавателя методически более оправдана. Обучение имеет дело со студентом, который одновременно и объект, и субъект процесса трансфера знаний. В таком ракурсе особенно важен персона- 
лизированный подход и мотивирующий диалог, ибо результат зависит от самого объекта, его желания учиться.

Метод синергетического стимулирования может оказаться действенным в групповых оффлайн-занятиях, когда преподаватель вдохновляет учащихся на совместный поиск решения, что поможет учащимся в будущем творчески решать проблемные задания, а не механически воспроизводить ответы. Обучение в дистанционной форме требует качественных разработок и персонализированного подхода к студентам, если мы хотим обучить высококвалифицированного специалиста, отличающегося от робота своим темпераментом, любознательностью, впечатлительностью и задатками творческих способностей.

\section{Источники}

Lingva-pro. 2020. Available at: https://lingva-pro.com/ru/ (accessed: 08. 06. 2020).

\section{Список литературы}

1. Андреева О.В. 2019. Формирование профессиональных компетенций бакалавров гуманитарного профиля в современном техническом вузе. В кн.: Современное образование: содержание, технологии, качество. Материалы XXV Международной научно-методической конференции, Санкт-Петербург, 23 апреля 2019 года. СПб., Издательство СПбГЭТУ «ЛЭТИ»: 623-625.

2. Вознесенская А.О., Шехонин А.А. 2019. Партнериат университета и индустрии. В кн.: Современное образование: содержание, технологии, качество. Материалы XXV Международной научно-методической конференции, Санкт-Петербург, 23 апреля 2019 года. СПб., Издательство СПбГЭТУ «ЛЭТИ»: 470-472.

3. Герасимова И.Г. 2019. Интернализирующие техники на занятии английским языком. В кн.: Современное образование: содержание, технологии, качество. Материалы XXV Международной научно-методической конференции, Санкт-Петербург, 23 апреля 2019 года. СПб., Издательство СПбГЭТУ «ЛЭТИ»: 343-346.

4. Ильченко Т.В., Максимова О.В. 2019. Формирование учебных действий в процессе изучения базовой дисциплины «Инженерная и компьютерная графика». В кн.: Современное образование: содержание, технологии, качество. Материалы XXV Международной научнометодической конференции, Санкт-Петербург, 23 апреля 2019 года. СПб., Издательство СПбГЭТУ «ЛЭТИ»: 125-128.

5. Лапин И.А., Лапина И.А. 2019. Психологическая готовность студента к обучению в коллеждах и вузах. В кн.: Современное образование: содержание, технологии, качество. Материалы XXV Международной научно-методической конференции, Санкт-Петербург, 23 апреля 2019 года. СПб., Издательство СПбГЭТУ «ЛЭТИ»: 584-586.

6. Меркулова В.А. 2019. Новая реальность в образовательной среде вуза. В кн.: Современное образование: содержание, технологии, качество. Материалы XXV Международной научно-методической конференции, Санкт-Петербург, 23 апреля 2019 года. СПб., Издательство СПбГЭТУ «ЛЭТИ»: 292-294.

7. Московчук Л.С. 2019. Влияние цифрового образования на компетентностную модель и профессиональный стандарт преподавателя. В кн.: Современное образование: содержание, технологии, качество. Материалы XXV Международной научно-методической конференции, Санкт-Петербург, 23 апреля 2019 года. СПб., Издательство СПбГЭТУ «ЛЭТИ»: 566-568.

8. Мякинькая А.В. 2019. Метаморфозы национальной системы преподавания. В кн.: Современное образование: содержание, технологии, качество. Материалы XXV Международной научно-методической конференции, Санкт-Петербург, 23 апреля 2019 года. СПб., Издательство СПбГЭТУ «ЛЭТИ»: 518-520.

9. Пояркова Ю.В. 2019. Инновационные технологии обучения. Электронные образовательные ресурсы. В кн.: Современное образование: содержание, технологии, качество. Материалы XXV Международной научно-методической конференции, Санкт-Петербург, 23 апреля 2019 года. СПб., Издательство СПбГЭТУ «ЛЭТИ»: 439-441. 
10. Сулоева Е.С., Романцова Н.В. 2019. Проблемы социальной адаптации под влиянием современных технологий. В кн.: Современное образование: содержание, технологии, качество. Материалы XXV Международной научно-методической конференции, Санкт-Петербург, 23 апреля 2019 года. СПб., Издательство СПбГЭТУ «ЛЭТИ»: 639-641.

11. Шабаева М.Б. 2019. Об оценивании результатов обучения в условиях перехода к стандартам 3++. В кн.: Современное образование: содержание, технологии, качество. Материалы XXV Международной научно-методической конференции, Санкт-Петербург, 23 апреля 2019 года. СПб., Издательство СПьГЭТУ «ЛЭТИ»: 554-557.

12. Шелудько В.Н., Кутузов В.М., Лысенко Н.В. 2019. Высшее профессиональное образование - глобальные вызовы 3-го тысячелетия. В кн.: Современное образование: содержание, технологии, качество. Материалы XXV Международной научно-методической конференции, Санкт-Петербург, 23 апреля 2019 года. СПб., Издательство СПбГЭТУ «ЛЭТИ»: 3-7.

13. Яковлева Т.Ю., Бобровский А.П., Дьяченко Н.В. 2019. Особенности обучения учащихся общеобразовательной школы для создания основы фундаментальной подготовки будущих специалистов. В кн.: Современное образование: содержание, технологии, качество. Материалы XXV Международной научно-методической конференции, Санкт-Петербург, 23 апреля 2019 года. СПб., Издательство СПбГЭТУ «ЛЭТИ»: 446-447.

14. Aspillera M. 2010. What Are the Potential Benefits of Online Learning? Education Guidance. WorldWideLearn. Available at: http://www.worldwidelearn.com/education-articles/benefitsof-online-learning.htm (accessed: 15. 12. 2019).

15. Graham C. 2006. Blended learning systems: Definition, current trends and future directions. In: The handbook of blended learning: Global perspectives, local designs. Eds. C.J. Bonk, C.R. Graham. San Francisco, Pfeiffer: 3-21.

16. Macdonald J. 2007. Blended Learning and On-line Tutoring. British Journal of Educational Technology, 38 (5): 943-955. DOI: doi.org/10.1111/j.1467-8535.2007.00749_10.x.

17. Miller G. 2014. History of Distance Learning. Education Guidance. American Inter Continental University Online. Available at: http://www.worldwidelearn.com/education-articles/historyof-distance-learning.html (accessed: 28. 11. 2019).

18. Oliver M., Trigwell K. 2005. Can ‘blended learning’be redeemed? E-learning, 2 (1): 17-26. DOI: 10.2304/elea.2005.2.1.17.

19. Stacey E., Gerbic P. 2009. Effective Blended Learning Practices: Evidence-Based Perspectives in ICT-Facilitated Education. Information Science Reference. Eds. E. Stacey, P. Gerbic. Hershey, New York, 358 p.

\section{References}

1. Andreeva O.V. 2019. Formirovanie professional'nykh kompetentsiy bakalavrov gumanitarnogo profilya v sovremennom tekhnicheskom vuze [Formation of professional competencies of bachelors in the humanities in a modern technical university]. In: Sovremennoe obrazovanie: soderzhanie, tekhnologii, kachestvo [Modern education: content, technology, quality]. Proceedings of the XXV International scientific and methodological conference, Saint Petersburg, April 23, 2019. SPb., Publ. SPbGETU «LETI»: 623-625.

2. Voznesenskaya A.O., Shekhonin A.A. 2019. Partneriat universiteta i industrii [University and Industry Partner]. In: Sovremennoe obrazovanie: soderzhanie, tekhnologii, kachestvo [Modern education: content, technology, quality]. Proceedings of the XXV International scientific and methodological conference, Saint Petersburg, April 23, 2019. SPb., Publ. Izdatel'stvo SPbGETU «LETI»: 470-472.

3. Gerasimova I.G. 2019. Internaliziruyushchie tekhniki na zanyatii angliyskim yazykom [Internalizing techniques in an English lesson]. In: Sovremennoe obrazovanie: soderzhanie, tekhnologii, kachestvo [Modern education: content, technology, quality]. Proceedings of the XXV International scientific and methodological conference, Saint Petersburg, April 23, 2019. SPb., Publ. Izdatel'stvo SPbGETU «LETI»: 343-346.

4. Il'chenko T.V., Maksimova O.V. 2019. Formirovanie uchebnykh deystviy v protsesse izucheniya bazovoy distsipliny «Inzhenernaya i komp'yuternaya grafika» [Formation of educational actions in the process of studying the basic discipline "Engineering and Computer Graphics"]. In: Sovremennoe obrazovanie: soderzhanie, tekhnologii, kachestvo [Modern education: content, technology, 
quality]. Proceedings of the XXV International scientific and methodological conference, Saint Petersburg, April 23, 2019.SPb., Publ. Izdatel'stvo SPbGETU «LETI»: 125-128.

5. Лапин И.А., Лапина И.А. 2019. Психологическая готовность студента к обучению в коллеждах и вузах [Psychological readiness of a student to study in colleges and universities.]. In: Sovremennoe obrazovanie: soderzhanie, tekhnologii, kachestvo [Modern education: content, technology, quality]. Proceedings of the XXV International scientific and methodological conference, Saint Petersburg, April 23, 2019. SPb., Publ. Izdatel'stvo SPbGETU «LETI»: 584-586.

6. Merkulova V.A. 2019. Novaya real'nost' v obrazovatel'noy srede vuza [New reality in the educational environment of the university]. In: Sovremennoe obrazovanie: soderzhanie, tekhnologii, kachestvo [Modern education: content, technology, quality]. Proceedings of the XXV International scientific and methodological conference, Saint Petersburg, April 23, 2019. SPb., Publ. Izdatel'stvo SPbGETU «LETI»: 292-294.

7. Moskovchuk L.S. 2019. Vliyanie tsifrovogo obrazovaniya na kompetentnostnuyu model' i pro-fessional'nyy standart prepodavatelya [The impact of digital education on the competence model and professional standard of the teacher]. In: Sovremennoe obrazovanie: soderzhanie, tekhnologii, kachestvo [Modern education: content, technology, quality]. Proceedings of the XXV International scientific and methodological conference, Saint Petersburg, April 23, 2019. SPb., Publ. Izdatel'stvo SPbGETU «LETI»: 566-568.

8. Myakin'kaya A.V. 2019. Metamorfozy natsional'noy sistemy prepodavaniya [Metamorphoses of the National Teaching System]. In: Sovremennoe obrazovanie: soderzhanie, tekhnologii, kachestvo [Modern education: content, technology, quality]. Proceedings of the XXV International scientific and methodological conference, Saint Petersburg, April 23, 2019. SPb., Publ. Izdatel'stvo SPbGETU «LETI»: 518-520.

9. Poyarkova Yu.V. 2019. Innovatsionnye tekhnologii obucheniya. Elektronnye obrazovatel'nye resursy [Innovative learning technologies. Electronic educational resources]. In: Sovremennoe obrazovanie: soderzhanie, tekhnologii, kachestvo [Modern education: content, technology, quality]. Proceedings of the XXV International scientific and methodological conference, Saint Petersburg, April 23, 2019. SPb., Publ. Izdatel'stvo SPbGETU «LETI»: 439-441.

10. Suloeva E.S., Romantsova N.V. 2019. Problemy sotsial'noy adaptatsii pod vliyaniem sovremen-nykh tekhnologiy [Problems of social adaptation under the influence of modern technologies]. In: Sovremennoe obrazovanie: soderzhanie, tekhnologii, kachestvo [Modern education: content, technology, quality]. Proceedings of the XXV International scientific and methodological conference, Saint Petersburg, April 23, 2019. SPb., Publ. Izdatel'stvo SPbGETU «LETI»: 639-641.

11. Shabaeva M.B. 2019. Ob otsenivanii rezul'tatov obucheniya v usloviyakh perekhoda $\mathrm{k}$ standartam 3++ [On the assessment of learning outcomes in the transition to $3++$ standards]. In: Sovremennoe obrazovanie: soderzhanie, tekhnologii, kachestvo [Modern education: content, technology, quality]. Proceedings of the XXV International scientific and methodological conference, Saint Petersburg, April 23, 2019. SPb., Publ. Izdatel'stvo SPbGETU «LETI»: 554-557.

12. Shelud'ko V.N., Kutuzov V.M., Lysenko N.V. 2019. Vysshee professional'noe obrazovanie global'nye vyzovy 3-go tysyacheletiya [Higher Professional Education - Global Challenges of the 3rd Millennium]. In: Sovremennoe obrazovanie: soderzhanie, tekhnologii, kachestvo [Modern education: content, technology, quality]. Proceedings of the XXV International scientific and methodological conference, Saint Petersburg, April 23, 2019. SPb., Publ. Izdatel'stvo SPbGETU «LETI»: 3-7.

13. Yakovleva T.Yu., Bobrovskiy A.P., D'yachenko N.V. 2019. Osobennosti obucheniya uchashchikhsya obshcheobrazovatel'noy shkoly dlya sozdaniya osnovy fundamental'noy podgotovki budushchikh spetsialistov [Features of teaching secondary school students to create the basis for the fundamental training of future specialists]. In: Sovremennoe obrazovanie: soderzhanie, tekhnologii, kachestvo [Modern education: content, technology, quality]. Proceedings of the XXV International scientific and methodological conference, Saint Petersburg, April 23, 2019. SPb., Publ. Izdatel'stvo SPbGETU «LETI»: 446-447.

14. Aspillera M. 2010. What Are the Potential Benefits of Online Learning? Education Guidance. WorldWideLearn. Available at: http://www.worldwidelearn.com/education-articles/benefitsof-online-learning.htm (accessed: 15. 12. 2019). 
15. Graham C. 2006. Blended learning systems: Definition, current trends and future directions. In: The handbook of blended learning: Global perspectives, local designs. Eds. C.J. Bonk, C.R. Graham. San Francisco, Pfeiffer: 3-21.

16. Macdonald J. 2007. Blended Learning and On-line Tutoring. British Journal of Educational Technology, 38 (5): 943-955. DOI: doi.org/10.1111/j.1467-8535.2007.00749_10.x.

17. Miller G. 2014. History of Distance Learning. Education Guidance. American Inter Continental University Online. Available at: http://www.worldwidelearn.com/education-articles/historyof-distance-learning.html (accessed: 28. 11. 2019).

18. Oliver M., Trigwell K. 2005. Can ‘blended learning’be redeemed? E-learning, 2 (1): 17-26. DOI: 10.2304/elea.2005.2.1.17.

19. Stacey E., Gerbic P. 2009. Effective Blended Learning Practices: Evidence-Based Perspectives in ICT-Facilitated Education. Information Science Reference. Eds. E. Stacey, P. Gerbic. Hershey, New York, 358 p.

\section{ИНФОРМАЦИЯ ОБ АВТОРЕ}

Панкратова Светлана Анатольевна, профессор кафедры иностранных языков СанктПетербургского государственного института кино и телевидения, г. Санкт-Петербург, Россия

\section{INFORMATION ABOUT THE AUTHOR}

Svetlana A. Pankratova, Professor of the Department of Foreign Languages, St. Petersburg State Institute of Cinema and Television, St. Petersburg, Russia 